\title{
HOW MUCH VARIATION IN THE MOLT DURATION OF PASSERINES CAN BE EXPLAINED BY THE GROWTH RATE OF TAIL FEATHERS?
}

\author{
Iván de la Hera, ${ }^{1,2,4}$ Sonja V. Schaper, ${ }^{2}$ José A. Díaz, ${ }^{1}$ Javier Pérez-Tris, ${ }^{1}$ \\ Staffan Bensch, ${ }^{3}$ ANd José Luis Tellería ${ }^{1}$ \\ ${ }^{1}$ Department of Zoology and Physical Anthropology, Faculty of Biology, Universidad Complutense de Madrid, 28040 Madrid, Spain; \\ ${ }^{2}$ Department of Animal Ecology, Netherlands Institute of Ecology (NIOO-KNAW), P.O. Box 50, 6700 AB Wageningen, The Netherlands; and \\ ${ }^{3}$ Department of Animal Ecology, Ecology Building, Lund University, 22362 Lund, Sweden
}

\begin{abstract}
In birds, molt duration is an important trait that can affect plumage functionality and, consequently, the fitness of individuals. However, knowledge about the factors that affect variation in molt speed is sparse, mostly because of the methodological difficulties of studying avian molt. We used a ptilochronology-based approach to estimate the rate at which tail feathers were produced during molt to shed light on the relationship between molt duration and feather growth rate. For that purpose, we used three data sets. First, we tested whether the average molt durations of 22 passerine species were correlated with the mean growth rates of their feathers, using both conventional and phylogenetically corrected statistical procedures. Second, we explored this same association among captive Great Tits (Parus major). And third, we took advantage of the biannual complete molt of Willow Warblers (Phylloscopus trochilus) to examine whether the feathers synthesized during their short summer molt grew faster than those produced during their long winter molt. Feather growth rates were negatively correlated with molt duration in all analyses, revealing that molt duration can be estimated from the growth rate of a single feather. However, predictive power was limited by the fact that molt duration is modulated mainly by molt intensity, which seems to be correlated with ecological constraints in our interspecific approach. We also discuss the implications of our results for the evolution of molt duration, and the potential application of ptilochronology in its study. Received 2 August 2010, accepted 21 December 2010.
\end{abstract}

Key words: comparative method, migration constraints, molt evolution, phenotypic diversity analysis programs (PDAP), phylogenetically independent contrasts.

\section{¿Cuánta Variación en la Duración de la Muda de los Paseriformes Puede Explicarse a Partir de la Tasa de Crecimiento de las Plumas de la Cola?}

RESUMEN.-La duración de la muda en las aves es un parámetro importante que puede afectar la funcionalidad del plumaje y, en consecuencia, la adecuación biológica de los individuos. Sin embargo, nuestro conocimiento sobre los factores que determinan la variación en la velocidad de la muda es escaso, debido principalmente a las dificultades metodológicas de su estudio. Mediante tres aproximaciones diferentes exploramos la relación entre la duración de la muda y la tasa de crecimiento individual de las plumas estimada mediante la técnica conocida como ptilocronología. En primer lugar, y empleando tanto métodos estadísticos convencionales como métodos de corrección filogenética, se evaluó si la duración media de la muda de 22 especies de paseriformes se correlacionó con la tasa de crecimiento de sus plumas de la cola. En segundo lugar, exploramos esta misma relación entre individuos de Parus major mantenidos en cautiverio. Y en tercer lugar, aprovechamos la muda completa bianual de Phylloscopus trochilus para examinar si las plumas producidas durante su muda estival crecieron más rápido que las plumas producidas durante su muda invernal más extensa. En todos los análisis, las tasas de crecimiento de las plumas se correlacionaron negativamente con la duración de la muda. Este resultado sugiere que la duración de la muda puede ser estimada a partir de la tasa de crecimiento de una única pluma. Sin embargo, el poder de predicción estuvo limitado por el hecho de que la duración de la muda parece estar principalmente modulada por la intensidad de la muda, la cual se asocia con restricciones ecológicas en nuestra aproximación interespecífica. Por último, se discuten las implicaciones de estos resultados en relación con la evolución de la duración de la muda y la utilidad de la ptilocronología en su estudio.

${ }^{4}$ E-mail: i.delahera@nioo.knaw.nl

The Auk, Vol. 128, Number 2, pages 321-329. ISSN 0004-8038, electronic ISSN 1938-4254. @ 2011 by The American Ornithologists' Union. All rights reserved. Please direct all requests for permission to photocopy or reproduce article content through the University of California Press's Rights and Permissions website, http://www.ucpressjournals. com/reprintInfo.asp. DOI: 10.1525/auk.2011.10181 
Molt IS A complex life-history trait that varies widely among species, populations, and individuals (Ginn and Melville 1983, Jenni and Winkler 1994). Some aspects of molt, such as its extent or phenology, are easy to identify and measure and have been used both for practical purposes (e.g., ageing; Svensson 1992, Jenni and Winkler 1994, Pyle 1997) and for the study of the ecological factors that determine their variation (Svensson and Hedenström 1999, Figuerola and Jovani 2001, Hall and Tullberg 2004). However, other traits, such as molt speed (or, conversely, molt duration; Jenni and Winkler 1994), are poorly known. This greatly restricts our understanding of the evolution of molt, because molt duration can affect the structure and functionality of the resulting feathers, and it can also interfere with other processes of the life cycle, such as breeding or migration (Dawson et al. 2000; Hall and Fransson 2000; Serra 2001; Dawson 2004; Serra et al. 2007; de la Hera et al. 2009a, b).

Variation in molt speed can be caused by two main factors: the individual growth rate of feathers and the number of feathers growing simultaneously (or molt intensity; Jenni and Winkler 1994). However, controversy exists over which of these is more important (Bensch and Grahn 1993, Jenni and Winkler 1994, Zenatello et al. 2002, Serra et al. 2010). Some authors attribute more relevance to molt intensity, assuming that this variable is more evolutionarily labile than the growth rate of feathers (Jenni and Winkler 1994, Rohwer et al. 2009). But other studies have revealed a large amount of within- and between-species variation in feather growth rate (Jenni and Winkler 1994, Oschadleus and Underhill 2008, de la Hera et al. 2009a), which suggests that the action of natural selection on this trait could cause much variation in molt speed (Butler et al. 2006, de la Hera et al. 2009a, Gienapp and Merilä 2010). Interestingly, this second view raises the question of whether molt speed can be predicted from the growth rate of a particular feather, because fast-molting birds are expected to show higher growth rates in all their feathers than slow-molting birds. However, the relationship between molt duration and the growth rate of individual feathers has not been explicitly evaluated before.

Although knowledge of the growth rate of individual feathers has the potential to describe variation in molt duration, growth rates of individual feathers have rarely been measured by a standardized procedure. Instead, feather growth rate has been traditionally estimated by studying the progression of primary feather molt in actively molting birds (i.e., molt scores; Ginn and Melville 1983). The drawback of this approach is that different feathers and different parts of the same feather can grow at different rates within the same individual (Bensch and Grahn 1993, Dawson 2003), making the results of studies that compare individuals in which feather growth rate is estimated in different parts of the wing equivocal. Moreover, such an approach is even more difficult in natural populations, because the prospects of recapturing birds during molt are low (Haukioja 1971) and, thus, very few individuals can be measured two or more times to obtain reliable estimates of feather growth rate (Jenni and Winkler 1994). Alternatively, feather growth rate can be determined on fully grown feathers by using their naturally produced daily growth bars, a technique called "ptilochronology" (Grubb 2006). Ptilochronology provides a more comparable estimate of feather growth rate, because the same feather and the same part of that feather is measured for all individuals. Thus, this method constitutes a suitable tool to explore the relationship between molt duration and feather growth rate. Additionally, and because of the universality of feather growth bars (Grubb 2006), ptilochronology has potential practical applications in field studies of molt duration (de la Hera et al. 2009b).

In the present study, we used three different data sets that describe duration of complete molts to assess the ability of feather growth rate (estimated by ptilochronology) to predict molt duration. First, we explored whether the mean feather growth rate of individual birds was correlated with molt duration in a sample of 22 passerine species for which the average molt duration was available in the literature (Ginn and Melville 1983). Secondly, a similar approach was applied within species to a group of captive Great Tits (Parus major) for which molt duration was recorded in aviaries. Third, we used the biannual molt of the Willow Warbler (Phylloscopus trochilus) to test for between-molt differences in feather growth rate. More explicitly, we used tail feathers collected from wild Willow Warblers to assess whether the feathers produced during their short summer molt grow faster than those synthesized during their long winter molt (Ginn and Melville 1983, Underhill et al. 1992).

\section{Methods}

Molt duration and feather growth rate between passerine species.Molt duration was obtained from Ginn and Melville (1983), who applied a standardized methodology (the regression of day of capture on primary molt progression) to molt data from British bird populations to estimate the number of days required by one individual to replace all of its primary feathers during a complete molt. Primary molt duration was used as a surrogate of overall molt duration because a complete molt event normally starts with the dropping of the innermost primary feathers, and finishes when the outermost primary feathers are fully grown (Ginn and Melville 1983, Jenni and Winkler 1994). Additionally, feather samples were obtained between June 1996 and February 2007 from birds that were mist netted in different woodlands on the Iberian Peninsula (for more details about study sites, see Tellería and Carbonell 1999) and in a wetland located in the north of Spain (Salburua Park, Álava). Given that feather growth bars are particularly conspicuous on tail feathers, one fifth rectrix feather was plucked from each individual to measure its growth rate. Only feathers produced during a complete molt process (i.e., adult feathers) were used. Adult feathers were distinguished from juvenile feathers (i.e., the first set of true feathers produced by fledglings) by their shape, consistency, and wear pattern (Svensson 1992, Jenni and Winkler 1994). We gathered molt duration data and feather samples for 22 passerine species (Table 1). Although feather samples were taken in the Iberian Peninsula, and molt data came from British breeding populations, this should not affect our results because between-species variance should be greater than within-species variation (see below), which is one of the basic assumptions of the comparative method in evolutionary biology (Harvey and Pagel 1991).

In the laboratory, the length of feather synthesized in 10 days (hereafter, "feather growth rate") was measured taking advantage of the light and dark band pattern perpendicular to the rachis that is naturally produced during feather development. Dark bands are 
TABLE 1. Estimates of molt duration obtained from Ginn and Melville (1983) and measurements of feather growth rate and length (means \pm SE) for the 22 passerine species included in the interspecific approach. The species abbreviations given in parentheses are used in Figure 2.

\begin{tabular}{|c|c|c|c|c|}
\hline Species & $\begin{array}{l}\text { Molt duration } \\
\quad \text { (days) }\end{array}$ & $\begin{array}{l}\text { Feather growth rate } \\
\text { (mm per } 10 \text { days) }\end{array}$ & $\begin{array}{l}\text { Feather length } \\
\qquad(\mathrm{mm})\end{array}$ & $n$ \\
\hline Sedge Warbler (Acrocephalus schoenobaenus) (Asc) & 65 & $23.75 \pm 0.37$ & $48.28 \pm 0.63$ & 9 \\
\hline Eurasian Reed Warbler (A. scirpaceus) (Asi) & 75 & $26.62 \pm 0.25$ & $54.91 \pm 0.44$ & 15 \\
\hline Long-tailed Tit (Aegithalos caudatus) (Aca) & 80 & $24.01 \pm 0.47$ & $58.36 \pm 1.07$ & 12 \\
\hline European Goldfinch (Carduelis carduelis) (Cca) & 70 & 26.91 & 51.22 & 1 \\
\hline European Greenfinch (C. chloris) (Cch) & 85 & $27.32 \pm 0.84$ & $57.45 \pm 1.58$ & 6 \\
\hline Blue Tit (Cyanistes caeruleus) (CYc) & 75 & $24.32 \pm 0.41$ & $53.86 \pm 0.58$ & 12 \\
\hline European Robin (Erithacus rubecula) (Eru) & 60 & $25.63 \pm 0.28$ & $61.98 \pm 0.57$ & 14 \\
\hline Common Chaffinch (Fringilla coelebs) (Fco) & 70 & $34.17 \pm 0.49$ & $70.85 \pm 0.78$ & 5 \\
\hline Eurasian Jay (Garrulus glandarius) (Ggl) & 92 & 54.41 & 148.86 & 1 \\
\hline Nightingale (Luscinia megarhynchos) (Lme) & 45 & $33.49 \pm 0.53$ & $69.42 \pm 0.66$ & 16 \\
\hline Corn Bunting (Miliaria calandra) (Mca) & 80 & 35.89 & 81.69 & 1 \\
\hline Great Tit (Parus major) (Pma) & 75 & $29.94 \pm 0.57$ & $66.71 \pm 0.75$ & 12 \\
\hline House Sparrow (Passer domesticus) (Pdo) & 60 & $31.72 \pm 1.49$ & $64.51 \pm 1.86$ & 2 \\
\hline Eurasian Tree Sparrow (P. montanus) (Pmo) & 60 & $30.70 \pm 0.47$ & $57.68 \pm 0.53$ & 6 \\
\hline Common Redstart (Phoenicurus phoenicurus) (Pph) & 40 & $30.37 \pm 1.37$ & $62.38 \pm 1.5$ & 2 \\
\hline Common Chiffchaff (Phylloscopus collybita) (Pco) & 45 & $23.70 \pm 1.2$ & $49.29 \pm 1.92$ & 4 \\
\hline European Magpie (Pica pica) (Ppi) & 110 & 51.77 & 156.50 & 1 \\
\hline Blackcap (Sy/via atricapilla) (Sat) & 47.5 & $30.78 \pm 0.3$ & $63.95 \pm 0.31$ & 54 \\
\hline Garden Warbler (S. borin) (Sbo) & 70 & $30.40 \pm 0.28$ & $59.04 \pm 0.38$ & 31 \\
\hline Whitethroat (S. communis) (Sco) & 40 & $33.47 \pm 1.31$ & $66.03 \pm 1.11$ & 5 \\
\hline Eurasian Blackbird (Turdus merula) (Tme) & 75 & $46.01 \pm 0.97$ & $116.07 \pm 1.37$ & 18 \\
\hline Song Thrush (T. philomelos) (Tph) & 50 & $40.74 \pm 0.19$ & $88.31 \pm 1.85$ & 2 \\
\hline
\end{tabular}

produced during the day and light bands during the night, so that one light plus one dark band (also known as a feather growth bar) corresponds to a 24-h period of feather growth (Brodin 1993). This band pattern allows estimation of the rate at which feathers are produced during molt. To avoid personal bias, the same person took all measurements (I. de la Hera). Feathers were placed on a black card, on which the length occupied by 10 growth bars on the leading edge of the feather was marked using two entomological pins. This measurement was always taken in the same part of the feather (i.e., 10 growth bars centered at approximately twothirds of the distance from the very bottom of the rachis; Grubb 2006). After removing the feather from the card, the distance between pins was measured using a digital caliper (Mitutoyo 500, resolution $0.01 \mathrm{~mm}$ ). We also measured the overall length of each feather to control for the potential effect of feather size on feather growth rate. To estimate the repeatability of feather traits, we calculated the intraclass correlation coefficient $\left(r_{i}\right)$ for feather growth rate and length using the 18 species for which at least two feather samples were collected (see Table 1). Such analyses revealed high and significant repeatabilities for feather growth rate $r_{i}=0.89$, $F=94.07, \mathrm{df}=17$ and 207, $P<0.001)$ and feather length $\left(r_{i}=0.97\right.$, $F=416.54, \mathrm{df}=17$ and 207, $P<0.001$ ), which suggests that feather traits estimated from a single individual (a circumstance that occurred in four species; Table 1) are representative of the species. For each species, the mean value of feather growth rate and feather length was used in statistical analyses (Table 1). Logarithmic transformation of feather growth rate and length provided better fit to a normal distribution $(P>0.05$ for both variables in the
Kolmogorov-Smirnov test after transformation), so we used log values of these variables in statistical analyses.

To assess the relationship between molt duration and feather growth rate, we performed a multiple regression analysis with molt duration as the dependent variable and feather growth rate and feather length as predictors (the correlation between feather growth rate and length was high and significant: $r=0.96, P<$ 0.001 ). We then repeated this analysis after considering the phylogenetic relationships between species. Although similar results are usually obtained in phylogenetic and nonphylogenetic approaches (Price 1997), the comparative method avoids the potential drawbacks associated with the use of species as statistically independent data (Garland et al. 1992). For the phylogenetic analysis, we used the phylogenetic independent contrasts (PICs) proposed by Felsenstein (1985). PICs were calculated using the program PDTREE on a phylogeny obtained from Jønsson and Fjeldså (2006; Fig. 1). Our working phylogeny lacked accurate estimates of the length of its branches in units of expected variance of character change. Consequently, we assumed a speciational model of evolutionary change in our comparative analyses, in which most of the change occurs in association with speciation events (Rohlf et al. 1990). Contrasts were successfully standardized prior to statistical analyses (in the three variables $P>0.273$ for the relationship between the standard deviation of the contrasts and the absolute value of the standardized contrasts). Additionally, our phylogenetic hypothesis was not completely resolved and showed two polytomies caused by insufficient phylogenetic information (i.e., soft polytomies; Maddison 1989). To take these uncertainties into 


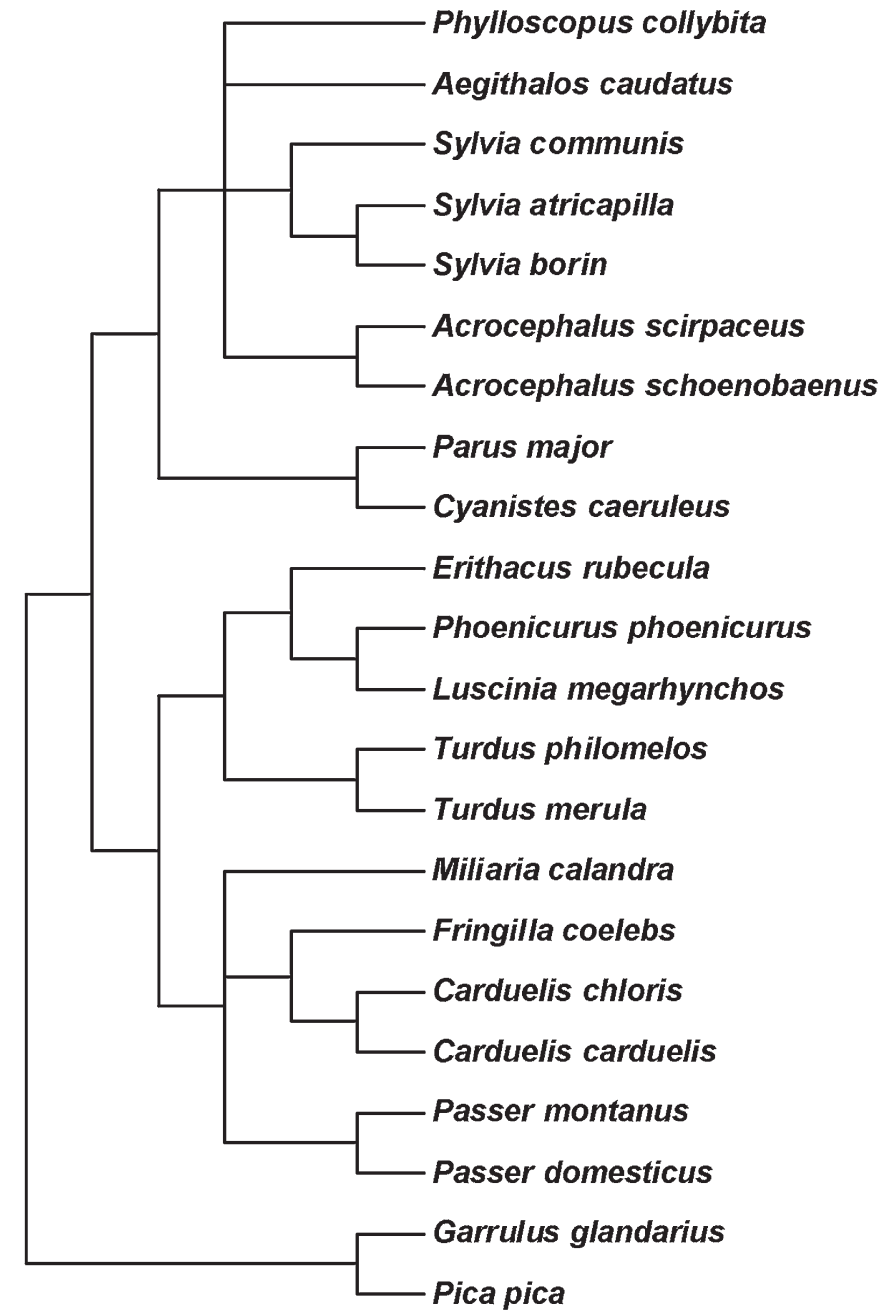

FIG. 1. Phylogenetic relationships among the 22 passerine species included in the interspecific analysis.

account and to maximize degrees of freedom without inflating Type I error rates (Garland and Díaz-Uriarte 1999), we applied the bounded-degrees-of-freedom approach suggested by Purvis and Garland (1993). As described by this method, we reduced the degrees of freedom for hypothesis testing from 19 to 16 (two and one degrees of freedom were subtracted because of the existence of two polytomies with four and three descending branches, respectively; see Purvis and Garland 1993).

To explore whether the residual variance of the interspecific analysis of molt duration could be explained by the temporal constraints that different species exhibit during molt, we categorized the species according to their migratory behavior (using the primary migratory behavior of the British populations, following Wernham et al. 2002) and the timing of their adults' complete molt (distinguishing between summer or winter molting species; see Ginn and Melville 1983, Jenni and Winkler 1994). Thus, we established three groups (see Fig. 2A): (1) sedentary species ( $n=11$; all molt in summer), (2) migratory species that molt on the breeding grounds before postbreeding migration $(n=8)$, and (3) migratory species that molt on the winter grounds after finishing autumn migration $(n=3)$. We performed an analysis of covariance (ANCOVA) to assess the contribution of this three-group factor to molt duration after controlling for feather growth rate and length.

To control for the effect of shared ancestry and obtain more reliable significance levels in this interspecific analysis, we created phylogenetically correct null distributions of $F$ statistics for ANCOVA, which allow setting critical values for hypothesis testing that account for the lack of independence among species (Garland et al. 1993). Thus, more correct $P$ values can be obtained by dividing the number of $F$ values derived from simulated data that exceed the empirical $F$ value (the one obtained in the conventional ANCOVA) by the number of simulations performed. These null distributions of $F$ statistics were obtained by generating 1,000 sets of simulated values of molt duration, feather growth rate, and feather length for the 22 species included in the study. Simulations were performed using PDSIMUL on the same data and phylogeny previously included in PDTREE. Again, we set all branch lengths equal to one, thereby assuming a speciational Brownianmotion model of evolutionary change. To avoid unrealistic data in the simulations, we bounded molt duration between the shortest value recorded in birds (28 days, in the Snow Bunting [Plectrophenax nivalis]) and the longest duration registered in passerines (182 days, for some large corvids; Jenni and Winkler 1994), and feather length between the values of the Palaearctic species with the shortest tail (Eurasian Wren [Troglodytes troglodytes]: $30 \mathrm{~mm}$ ) and that with the longest tail (Common Raven [Corvus corax]: $245 \mathrm{~mm}$; Cramp and Perrins 1994). The lower and upper limits for feather growth rate were estimated using the regression of feather growth rate on feather length for the 22 species analyzed $\left(\log _{10}\right.$ feather growth rate $=0.202+0.706 * \log _{10}$ feather length) and the above values of tail length for the Eurasian Wren and the Common Raven. We selected the REPLACE option of PDSIMUL to keep the traits in bounds during the simulations. We used the betweenspecies means of real data as both starting values and expected means of simulated tip values. The expected variances of the simulated tip data were set equal to the variances of the real data. To ensure that different traits were evolving independently, the correlation between simulated changes for traits was set to zero. Finally, we used a conventional statistical program (STATISTICA, version 9; StatSoft, Tulsa, Oklahoma) to calculate the corresponding $F$ values for each of the 1,000 sets of simulated data.

Molt duration and feather growth rate in captive Great Tits.The relationship between molt duration and feather growth rate and length was also compared among individuals of the same species. For this purpose, we used a captive group of Great Tits originally captured as nestlings at the Hoge Veluwe National Park, The Netherlands. Nestlings were moved to the facilities of the Netherlands Institute of Ecology located in Heteren in spring 2008 These birds started their first complete molt in summer 2009 after more than one year of captivity. We monitored the progression of primary molt in 59 Great Tits weekly, assigning each of the 10 primary feathers on the right wing a score: $0=$ old, nonmolted feather or recently dropped feather; 1 = approximately one-quarter grown (i.e., from eruption from the follicle to onethird fully grown); 2 = approximately half grown (i.e., one-third to two-thirds fully grown); 3 = approximately three-quarters grown; and $4=$ fully grown. From this information, the molt duration of 
each individual was calculated via the molt score index suggested by Dawson and Newton (2004), in which the relative contribution of each primary feather to total primary feather mass is taken into account to obtain more accurate estimates of molt duration (for the case of the Great Tit, see Dawson 2005). Additionally, we also estimated molt intensity for each individual from the mean number of simultaneously growing primary feathers (i.e., number or primaries in stage 1, 2, or 3) during our weekly checks. For this calculation, we considered only the data recorded during intermediate stages of primary molt (i.e., when the total molt score of the birds following our $0-5$ nomenclature was between 10 and 30). This was done to avoid the potential problems of a reduced number of feathers growing simultaneously during the earliest and latest stages of molt (Bensch and Grahn 1993). We used this index of molt intensity to explore its effects on molt duration, on feather growth rate, and on the relationship between both.

After the completion of molt, both fifth rectrix feathers were also collected from each bird, and feather growth rate and length were measured following the methods described above. Given that some feathers were absent, malformed, or lacked visible growth bars, three Great Tits were excluded from the analyses, and for eight individuals only one feather could be measured. We used the remaining 48 individuals with two measurements of feather growth rate to estimate the within-individual repeatability of this trait, which was high and significant $\left(r_{i}=0.73, F=6.54, \mathrm{df}=47\right.$ and $48, P<0.001$ ). These 48 individuals (for which we considered the mean values of both feathers), together with the 8 birds with only one measurement, were used in a multiple regression analysis that investigated the relationship between molt duration and feather traits (feather growth rate and length were also correlated with each other: $r=0.42, P=0.001$ ). This analysis included a number of Great Tits that belonged to the same brood (53 Great Tits had at least one sibling in the final sample, and there were 13 families with 2-7 members). For these 53 individuals, familial effects were not significant when included in the model that analyzed molt duration in relation to feather growth rate and length $(F=1, \mathrm{df}=12$ and $38, P=0.468)$, and they did not affect molt duration $(F=1.34$, $\mathrm{df}=12$ and $40, P=0.236)$, feather length $(F=0.53, \mathrm{df}=12$ and $40, P=0.881$ ), length-adjusted feather growth rate (familial effect: $F=1.2, \mathrm{df}=12$ and 39, $P=0.319$; feather length effect: $F=13.3$, $\mathrm{df}=1$ and $39, P<0.001)$, or molt intensity $(F=1, \mathrm{df}=12$ and 40 , $P=0.467)$. Consequently, we considered all individuals as independent data to increase the statistical power of our analyses.

The biannual molt of the Willow Warbler.-The Willow Warbler is the only species in the Western Palaearctic region in which adult birds perform two complete molts per year (i.e., biannual molt; Cramp 1992, Jenni and Winkler 1994). One of them is carried out on European territories after breeding, and the other one takes place in African wintering grounds after autumn migration and prior to northward spring migration. Several studies have demonstrated that summer molt is shorter (with a mean molt duration of 40 days) than winter molt ( $\sim 70$ days; Ginn and Melville 1983, Underhill et al. 1992), which provides a suitable setting to evaluate whether feather growth rate predicts between-molt differences in duration in this species.

We collected one fifth rectrix tail feather from 46 adult Willow Warblers of the subspecies P. t. trochilus (Cramp 1992). Birds were captured during migration periods in the Iberian Peninsula
(August and September 2006, and March 2007) and during breeding in southern Sweden (May 2000 and June 2007). Of these 46 feathers, 19 were produced during the summer complete molt, and 27 were grown during the winter molt. In the laboratory, we calculated feather growth rate and length following the same methods described above. Feather growth rate was calculated twice for all individuals to provide an estimate of within-feather repeatability, which was very high and significant $\left(r_{i}=0.91, F=20.56, \mathrm{df}=\right.$ 45 and $46, P<0.001$ ). We used the mean value of both measurements in the analysis of the differences in feather growth rate between the summer and the winter molt. For this, we performed an ANCOVA with feather growth rate as the dependent variable, summer and winter molt as the categorical predictor, and feather length as the covariate.

All the regression coefficients reported in the results are standardized regression coefficients $(\beta)$. We also showed the corresponding standard errors of these coefficients \pm SE.

\section{Results}

Feather growth rate was negatively correlated with molt duration $(F=6.54, \mathrm{df}=1$ and $19, P=0.019, \beta=-1.487 \pm 0.581)$ after controlling for feather length $(F=11, \mathrm{df}=1$ and $19, P=0.004, \beta=1.928 \pm$ 0.581 ) in the conventional interspecific analysis (Fig. 2A). These results did not change qualitatively in the phylogenetic analysis using PICs (feather growth rate effect: $F=6.72$, df $=1$ and $19, P=0.018$, $\beta=-1.105 \pm 0.426$; feather length effect: $F=10.29, \mathrm{df}=1$ and 19 , $P=0.005, \beta=1.368 \pm 0.426$ ), even with reduced degrees of freedom due to the existence of two soft polytomies in the phylogeny (recalculated $P$ values with 16 instead of 19 degrees of freedom: 0.02 and 0.005 for feather growth rate and feather length, respectively). Feather growth rate and length explained nearly half of the amongspecies variation in molt duration $\left(R^{2}=0.45\right)$. The inclusion in the model of the three-way factor that accounted for the among-species differences in the temporal constraints experienced during molt (i.e., different combination of migratory behavior and molt phenology) explained part of the remaining residual variance of molt duration $(F=8.67, \mathrm{df}=2$ and 17 , conventional $P=0.003$, phylogenetically correct $P=0.013$ ), increasing the coefficient of determination of the model from 0.45 to 0.73 . Thus, sedentary species and migratory species that postponed molt to the winter period showed longer molts than migratory species that molt on breeding grounds immediately before autumn migration (Fig. 2B).

For Great Tits, we also obtained a significant negative association between feather growth rate and molt duration (feather growth rate effect: $F=7.87, \mathrm{df}=1$ and $53, P=0.007, \beta=-0.382 \pm$ 0.136 ; Fig. 3A) after controlling for the effect of feather length $(F=$ $10.21, \mathrm{df}=1$ and $53, P=0.002, \beta=0.435 \pm 0.136)$. However, the ability of feather growth rate and length to predict molt duration was low $\left(R^{2}=0.19\right)$. When the effect of molt intensity was also included in the model $(F=31.42, \mathrm{df}=1$ and $52, P<0.001, \beta=-0.605 \pm 0.108)$, the coefficient of determination increased from 0.19 to 0.50 , but feather growth rate and length became statistically nonsignificant (feather growth rate effect: $F=3.68, \mathrm{df}=1$ and $52, P=0.060$, $\beta=-0.216 \pm 0.112$; feather length effect: $F=1.9, \mathrm{df}=1$ and $52, P=$ $0.174, \beta=0.164 \pm 0.119$ ). Thus, positive residuals of molt duration on feather growth rate and length corresponded to Great Tits with relatively few primary feathers in simultaneous growth (low molt 

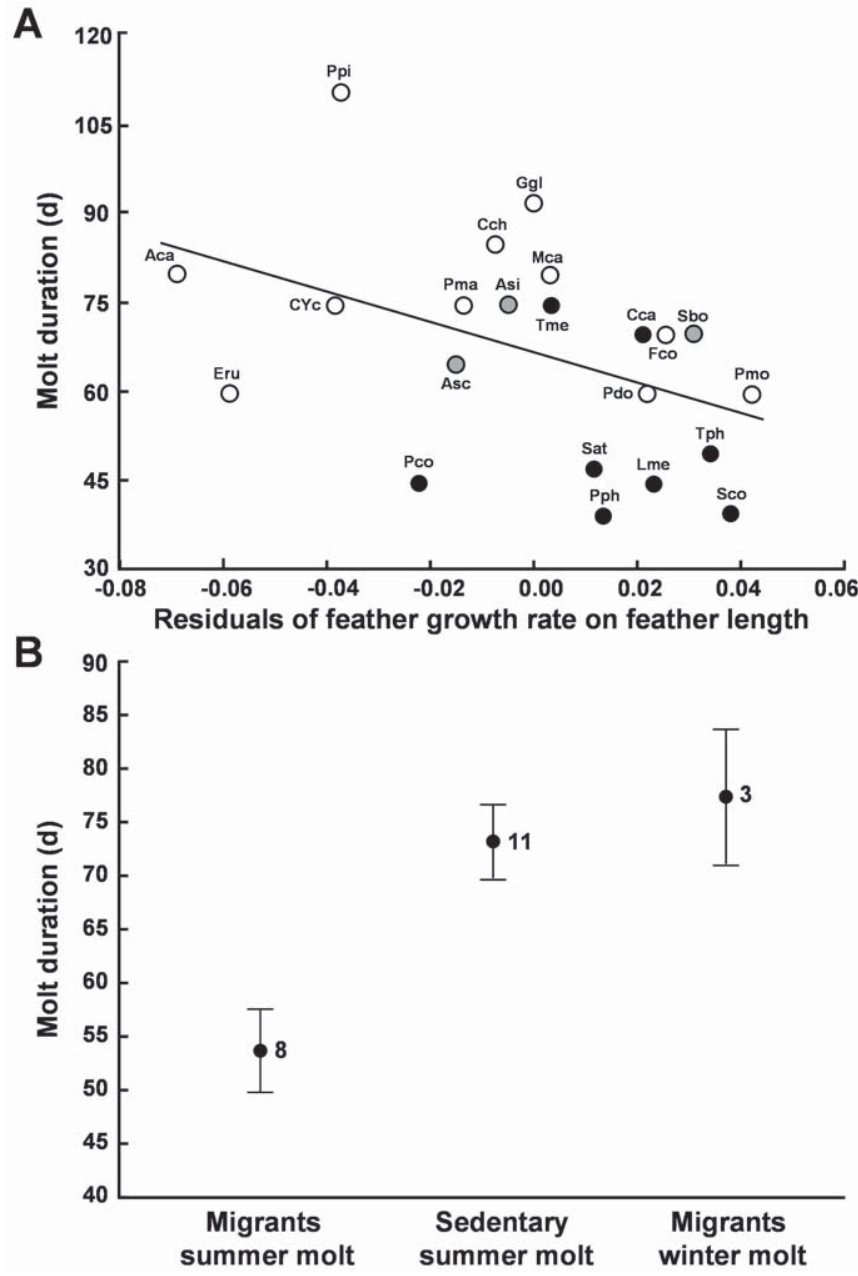

FIG. 2. (A) Relationship between molt duration and the residuals of feather growth rate on feather length for the 22 passerine species considered in the interspecific analysis (abbreviations are defined in Table 1). Black dots represent migratory species that molt in summer, gray circles represent migratory birds that have postponed molt to the winter period, and open circles show sedentary species. (B) Variation in molt duration among the three groups of species described in (A) (graph shows means adjusted by feather traits, with SE and sample sizes).

intensity), whereas negative residuals corresponded to birds with a larger number of feathers in simultaneous growth (high molt intensity; Fig. 3B). Accordingly, molt intensity alone explained nearly as much variation in molt duration (molt intensity effect on molt duration: $F=45.92, \mathrm{df}=1$ and $54, P<0.001, \beta=-0.678 \pm$ $0.1, R^{2}=0.46$ ) as the model that included all explanatory variables (i.e., molt intensity, feather growth rate, and feather length), and much more variation than the model that considered only feather growth rate and length. Furthermore, when we analyzed molt in tensity in relation to feather length and feather growth rate, we detected a significant negative correlation with the former $(F=10.54$, $\mathrm{df}=1$ and $53, P=0.002, \beta=-0.448 \pm 0.138)$, and a nearly significant positive association with the latter $(F=3.95, \mathrm{df}=1$ and $53, P=$ $0.052, \beta=0.274 \pm 0.138$ ).
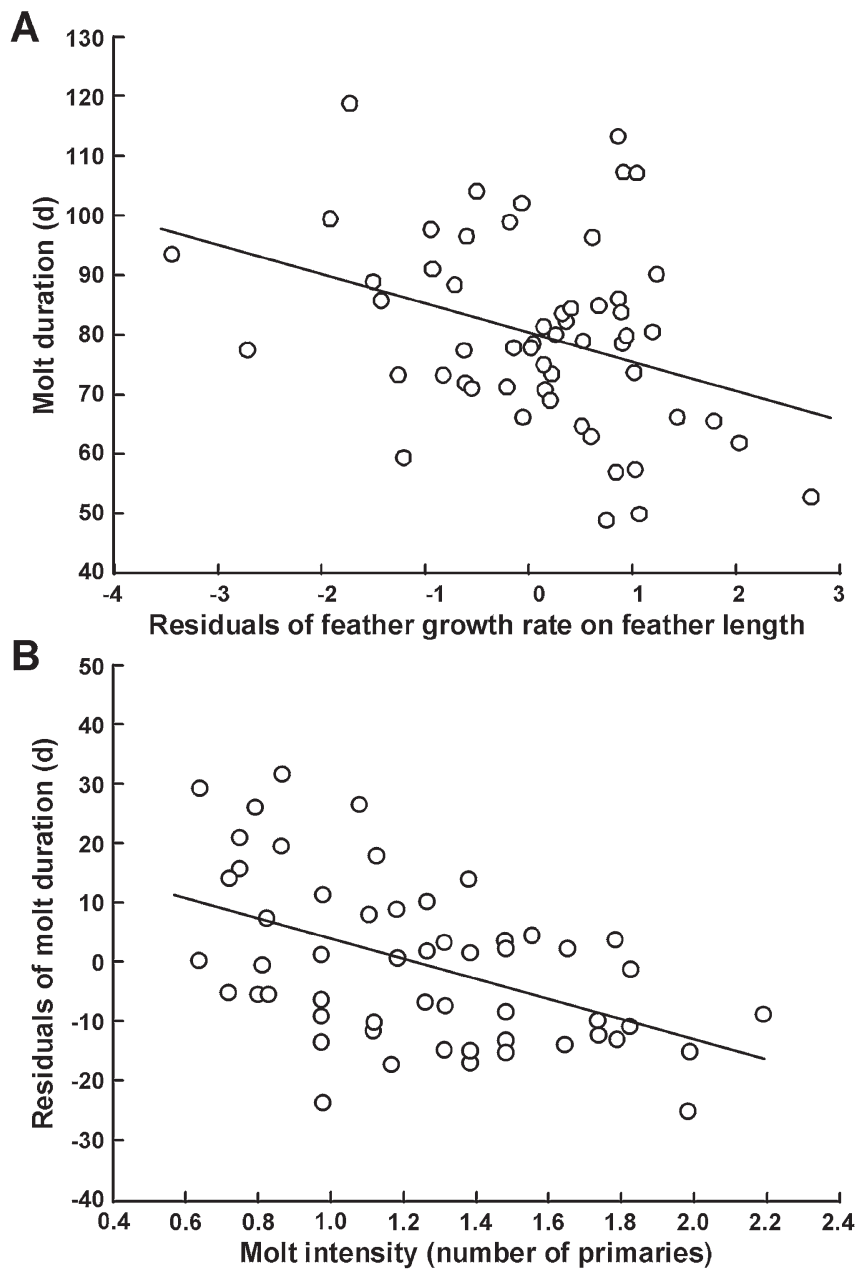

FIG. 3. (A) Relationship between molt duration and the residuals of feather growth rate on feather length in captive Great Tits. (B) Relationship between the residuals of molt duration on feather traits and an index of molt intensity obtained from the mean number of primary feathers growing simultaneously during intermediate stages of primary molt.

Finally, feathers produced during the summer molt of the Willow Warbler had faster growth rates than those produced during the winter molt $(F=6.94, \mathrm{df}=1$ and $43, P=0.012$; Fig. 4$)$ after controlling for the effect of feather length $(F=51.92, \mathrm{df}=1$ and 43 , $P<0.001, \beta=0.788 \pm 0.109$ ). However, the difference in feather growth rate between molts in the Willow Warbler was only $5 \%$, much lower than the $40 \%$ difference in molt duration (of 30 days) between the summer and the winter molts.

\section{Discussion}

Our results indicate that feather growth rate is negatively correlated with molt duration both within and between species, confirming that molt duration can be partially predicted from the growth rate of a single feather. Thus, rapidly molting birds showed higher growth rates in their tail feathers than slowly molting ones, a pattern that was detected using three different approaches. 


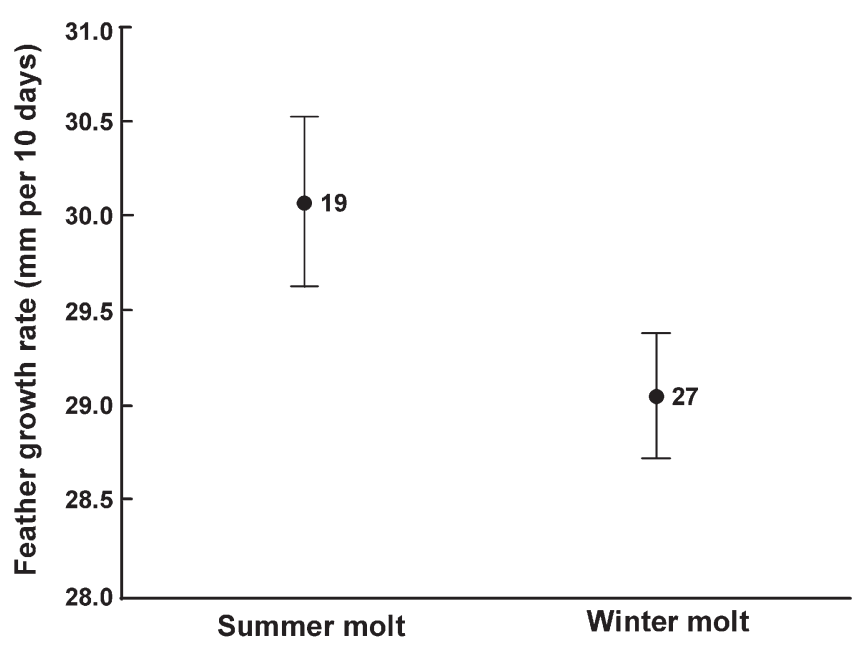

FIG. 4. Variation in feather growth rate between the summer and winter molts of the Willow Warbler. The graph shows mean values adjusted for feather length, with SE and sample sizes.

Interestingly, the database obtained from captive Great Tits made possible the analysis of the effects of molt intensity and feather growth rate on molt duration in a single linear model, which allowed us to assess the relative contribution of each of these main components to molt speed. These analyses revealed that, when the number of feathers growing simultaneously is taken into account, the effect of feather growth rate on molt duration is very small (it became marginally significant in the model). This result supports the idea that molt intensity plays a more important role than feather growth rate in modulating molt speed in this species. However, the effects of molt intensity and feather growth rate on molt duration were difficult to disentangle because both variables were positively intercorrelated. Thus, Great Tits that had more feathers growing simultaneously also showed faster feather growth rates. This result rules out the existence of a tradeoff between molt intensity and feather growth rate (Bensch and Grahn 1993) and suggests that molt intensity cannot confound the relationship between molt duration and feather growth rate. This fact would support the usefulness of ptilochronology on adult feathers as a technique to obtain information about molt speed in birds (de la Hera et al. 2009b).

Although ptilochronology is limited by the fact that not all feathers are equally measureable (Grubb 2006), this technique has several advantages over the traditional methods used to study the growth rate of feathers (Underhill and Zucchini 1988, Underhill et al. 1990, Bensch and Grahn 1993, Rothery and Newton 2002). For example, it avoids the potential drawback of estimating feather growth rate in different feathers or different parts of the same feather (Bensch and Grahn 1993, Dawson 2003). Furthermore, this technique can be applied when birds are not molting and are easier to capture, which could reduce the time and effort necessary to obtain reasonable sample sizes to test our hypothesis. Consequently, ptilochronology could be practical for exploring molt duration in rare birds or in species that are particularly difficult to capture during the molt, and it could provide a useful tool to improve our knowledge of the ecological correlates and evolutionary significance of molt duration in birds.
In addition to the observed relationship between molt duration and feather growth rate and length, the exploration of the residuals derived from such analysis in the interspecific approach showed other interesting results. Thus, negative residuals in that analysis would correspond to species whose molt duration is shorter than expected on the basis of their feather growth rate (Fig. 2A), and, therefore, they necessarily would have relatively more feathers in simultaneous growth (high-molt-intensity species), whereas the contrary is expected for species with positive residuals, which would have relatively few feathers in simultaneous growth (low-molt-intensity species). Interestingly, these residuals were associated with the among-species differences in migratory behavior and molt timing, two major determinants of the temporal constraints experienced by birds during molt. Thus, molt intensity would be higher in summer-molting migrants, because their molt is forced to fit within the short time gap available between the end of breeding and the autumn migration (Svensson and Hedenström 1999, Hall and Tullberg 2004, de la Hera et al. 2009a). On the other hand, temporal pressures are not as strong for sedentary species and winter molting migrants (de la Hera et al. 2009a, 2010), so they can afford a slower molt that would reduce the risk of predation and the high flight costs experienced when many flight feathers are molted simultaneously (Jenni and Winkler 1994, Williams and Swaddle 2003).

Feather growth rate successfully predicted the existence of differences in molt duration between the summer and winter molts of the Willow Warbler (Ginn and Melville 1983, Underhill et al. 1992). However, such differences in feather growth rate were relatively low compared to differences in molt duration, which suggests that molt intensity also plays a more important role in the shortening of summer molt in relation to winter molt. Remarkably, the Willow Warbler is the only species for which a detailed study of the two main components of molt speed exists (i.e., individual feather growth rate and molt intensity). Thus, rapidly molting Willow Warblers have both faster feather growth rates and more feathers growing simultaneously than slowly molting Willow Warblers during the summer molt (Bensch and Grahn 1993). Such an observation, together with the positive correlation between molt intensity and feather growth rate observed in this study of the Great Tit, suggests that significant reductions in molt duration are possible only by increasing both feather growth rate and molt intensity.

\section{ACKNOWLEDGMENTS}

This study was funded by the Spanish Ministry of Science and Technology (projects CGL2004-02744/BOS, CGL2007-62937/ BOS, and CGL2007-60277/BOS) and the Department of Education, Universities and Research of the Basque Government (studentships BFI. 04-33 and 09-13). This research was possible thanks to the permits granted by the corresponding authorities: Diputación Foral de Âlava, Comunidad Autónoma de Madrid, Junta de Andalucía and Royal Netherlands Academy of Arts and Sciences (DEC protocol CTE.08.09). We are particularly indebted to A. Onrubia and A. Unanue for their valuable help during feather collection in the field, and to H. Wiggers for her help scoring the molt of Great Tits. 


\section{Literature Cited}

BensCh, S., And M. GRahn. 1993. A new method for estimating individual speed of molt. Condor 95:305-315.

Brodin, A. 1993. Radio-ptilochronology tracing radioactively labelled food in feathers. Ornis Scandinavica 24:167-173.

Butler, L. K., S. Rohwer, And M. Rogers. 2006. Prebasic molt and molt-related movements in Ash-throated Flycatchers. Condor 108:647-660.

Cramp, S. 1992. Handbook of the Birds of Europe, the Middle East and North Africa. The Birds of the Western Palearctic, vol. 6: Warblers. Oxford University Press, Oxford, United Kingdom.

Cramp, S., and C. M. Perrins. 1994. Handbook of the Birds of Europe, the Middle East and North Africa. The Birds of the Western Palearctic, vol. 8: Crows to Finches. Oxford University Press, Oxford, United Kingdom.

DAwson, A. 2003. A detailed analysis of primary feather moult in the Common Starling Sturnus vulgaris-New feather mass increases at a constant rate. Ibis 145:E69-E76.

Dawson, A. 2004. The effects of delaying the start of molt on the duration of molt, primary feather growth rates and feather mass in Common Starlings Sturnus vulgaris. Ibis 146:493-500.

DAwson, A. 2005. The scaling of primary flight feather length and mass in relation to wing shape, function and habitat. Ibis 147:283292.

Dawson, A., S. A. Hinsley, P. N. Ferns, R. H. C. Bonser, And L. ECCLESTON. 2000. Rate of molt affects feather quality: A mechanism linking current reproductive effort to future survival. Proceedings of the Royal Society of London, Series B 267:2093-2098.

DAwsOn, A., AND I. NEwTON. 2004. Use and validation of a molt score index corrected for primary-feather mass. Auk 121:372379.

de la Hera, I., J. A. Díaz, J. Pérez-Tris, and J. L. Tellería. 2009a. A comparative study of migratory behaviour and body mass as determinants of moult duration in passerines. Journal of Avian Biology 40:461-465.

de la Hera, I., J. Pérez-Tris, and J. L. Tellería. 2009b. Migratory behaviour affects the trade-off between feather growth rate and feather quality in a passerine bird. Biological Journal of the Linnean Society 97:98-105.

de la Hera, I., J. Pérez-Tris, and J. L. Tellería. 2010. Relationships among timing of moult, moult duration and feather mass in long-distance migratory passerines. Journal of Avian Biology 41:609-614.

Felsenstein, J. 1985. Phylogenies and the comparative method. American Naturalist 125:1-15.

FiguerolA, J., AND R. JovANi. 2001. Ecological correlates in the evolution of moult strategies in Western Palearctic passerines. Evolutionary Ecology 15:183-192.

Garland, T., JR., And R. Díaz-Uriarte. 1999. Polytomies and phylogenetically independent contrasts: Examination of the bounded degrees of freedom approach. Systematic Biology 48:547-558.

Garland, T., Jr., A. W. Dickerman, C. M. Janis, And J. A. Jones. 1993. Phylogenetic analysis of covariance by computer simulation. Systematic Biology 42:265-292.

Garland, T., JR., P. H. Harvey, And A. R. Ives. 1992. Procedures for the analysis of comparative data using phylogenetically independent contrasts. Systematic Biology 41:18-32.
Gienapp, P., And J. Merilä. 2010. Genetic and environmental effects on a condition-dependent trait: Feather growth in Siberian Jays. Journal of Evolutionary Biology 23:715-723.

Ginn, H. B., ANd D. S. Melville. 1983. Molt in Birds. BTO, Tring, United Kingdom.

GrubB, T. C., JR. 2006. Ptilochronology: Feather Time and the Biology of Birds. Oxford University Press, Oxford, United Kingdom.

HALl, K. S. S., AND T. FRAnsSON. 2000. Lesser Whitethroats under time-constraint moult more rapidly and grow shorter wing feathers. Journal of Avian Biology 31:583-587.

Hall, K. S. S., And B. S. Tullberg. 2004. Phylogenetic analyses of the diversity of moult strategies in Sylviidae in relation to migration. Evolutionary Ecology 18:85-105.

Harvey, P. H., And M. D. PAgel. 1991. The Comparative Method in Evolutionary Biology. Oxford University Press, Oxford, United Kingdom.

Haukioja, E. 1971. Flightlessness in some moulting passerines in Northern Europe. Ornis Fennica 48:101-116.

Jenni, L., AND R. Winkler. 1994. Molt and Ageing of European Passerines. Academic Press, London.

JønSSON, K. A., AND J. FJELDSÅ. 2006. A phylogenetic supertree of oscine passerine birds (Aves: Passeri). Zoologica Scripta 35:149_ 186.

MAdDISON, W. P. 1989. Reconstructing character evolution on polytomous cladograms. Cladistics 5:365-377.

Oschadleus, H. D., AND L. G. Underhill. 2008. Primary moult of adult Red-billed Queleas (Quelea quelea) in southern Africa in relation to patterns of movement. Emu 108:331-339.

PRICE, T. 1997. Correlated evolution and independent contrasts Philosophical Transactions of the Royal Society of London, Series B 352:519-529.

Purvis, A., And T. Garland, JR. 1993. Polytomies in comparative analyses of continuous characters. Systematic Biology 42:569-575.

Pyle, P. 1997. Identification Guide to North American Birds, Part 1 Columbidae to Ploceidae. Slate Creek Press, Bolinas, California.

Rohlf, F. J., W. S. Chang, R. R. Sokal, And J. Kim. 1990. Accuracy of estimated phylogenies: Effects of tree topology and evolutionary model. Evolution 44:1671-1684.

Rohwer, S., R. E. Ricklefs, V. G. Rohwer, and M. M. Copple. 2009. Allometry of the duration of flight feather molt in birds. PLoS Biology 7:e1000132.

Rothery, P., AND I. NeWton. 2002. A simple method for estimating timing and duration of avian primary moult using field data. Ibis 144:526-528.

SerRA, L. 2001. Duration of primary moult affects primary quality in Grey Plovers Pluvialis squatarola. Journal of Avian Biology 32:377-380.

Serra, L., M. Griggio, D. Licheri, and A. Pilastro. 2007. Molt speed constrains the expression of a carotenoid-based sexual ornament. Journal of Evolutionary Biology 20:2028-2034.

Serra, L., S. Pirrelo, D. Licheri, M. Griggio, and A. Pilastro. 2010. Sex-dependent response of primary moult to simulated time constraints in the Rock Sparrow Petronia petronia. Journal of Avian Biology 41:327-335.

Svensson, E., And A. Hedenström. 1999. A phylogenetic analysis of the evolution of moult strategies in Western Palearctic warblers (Aves: Sylviidae). Biological Journal of the Linnean Society 67:263-276. 
Svensson, L. 1992. Identification Guide to European Passerines. L. Svensson, Stockholm.

Tellería, J. L., And R. CARbonell. 1999. Morphometric variation of five Iberian Blackcap Sylvia atricapilla populations. Journal of Avian Biology 30:63-71.

Underhill, L. G., R. P. Prys-Jones, R. J. Dowsett, P. Herroelen, D. N. Johnson, M. R. Lawn, S. C. Norman, D. J. Pearson, AND A. J. TREe. 1992. The biannual primary moult of Willow Warblers Phylloscopus trochilus in Europe and Africa. Ibis 134: 286-297.

UNDERHILL, L. G., AND W. ZUCCHINI. 1988. A model for avian primary moult. Ibis 130:358-372.

Underhill, L. G., W. Zucchini, and R. W. Summers. 1990. A model for avian primary moult-data types based on migration strategies and example using the Redshank Tringa totanus. Ibis 132:118-123.

Wernham, C. V., T. P. Toms, J. H. Marchant, J. A. Clark, G. M. Siriwardena, and S. R. Baillie, Eds. 2002. The Migration Atlas: Movements of the Birds of Britain and Ireland. T. \& A. D. Poyser, London.

Williams, E. V., AND J. P. SwaddLE. 2003. Moult, flight performance and wingbeat kinematics during take-off in European Starlings Sturnus vulgaris. Journal of Avian Biology 34:371-378.

Zenatello, M., L. Serra, and N. Baccetti. 2002. Trade-offs among body mass and primary moult patterns in migrating Black Terns Chlidonias niger. Ardea 90:411-420.

Associate Editor: K. J. McGraw 